\title{
Rancang Bangun Sistem Monitoring Tinggi Muka Air di Wilayah Danau Toba
}

\author{
Design on Water Level Monitoring System in Lake Toba Area \\ Maulana Putra $^{1^{*}}$, Dyah P. Djenal' ${ }^{2}$, Fajar Giri Suseno ${ }^{3}$, Tiven Sandro ${ }^{4}$ \\ ${ }^{1,2,3,4}$ Badan Meteorologi Klimatologi dan Geofisika
}

\begin{tabular}{l}
\hline \hline ARTICLE INFO \\
\hline Article history: \\
DOI: \\
10.30595/pspfs.v1i.129 \\
Submitted: \\
June 23, 2021 \\
Accepted: \\
July 13, 2021 \\
Published: \\
Oct 31, 2021
\end{tabular}

\section{Keywords:}

Water Level, Lake Toba

\begin{abstract}
Lake Toba is a tecto-volcanic lake located in North Sumatra Province, Indonesia. Currently, Lake Toba is 1 (one) of 5 (five) Super Priority Tourism Destinations (DPSP) prepared by the Government of Indonesia. This study made a design for a water level monitoring system in the Lake Toba region. This system design is one form of mitigation, namely an effort to reduce disaster risk. The design of the Water Level Monitoring System in the Lake Toba Region used several components, namely Data Loggers, Sensors, and supporting equipment such as power supplies and communication systems. The Water Level Monitoring System in the Lake Toba Region was built in 6 (six) locations, namely Ajibata Port, Ambarita Port, Simanindo Port, Muara Port, Sippingan Port, and Balige Port. The observation of the monitoring system in the Lake Toba region showed that the water level and data quality vary. The sensor in this system can identify changes in water level in the Lake Toba region with a small amplitude of $10-15$ centimeters.
\end{abstract}

This work is licensed under a Creative Commons Attribution 4.0 International License.

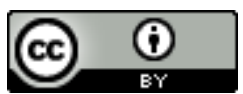

\section{Corresponding Author:}

Maulana Putra

Badan Meteorologi Klimatologi dan Geofisika

J1. Angkasa I, No.2 Kemayoran Jakarta Pusat 10720 Jakarta, Indonesia

Email: tivensandro@gmail.com

\section{PENDAHULUAN}

Danau Toba adalah sebuah danau tekto-vulkanik yang terletak di Provinsi Sumatera Utara, Indonesia. Danau ini merupakan danau terbesar di Indonesia dan Asia Tenggara. Danau Toba memiliki Luas 436 mil $^{2}$, panjang 62,14 mil, ketinggian permukaan $2.696 \mathrm{ft}$, lebar 18,64 mil, dan volume 57,58 mil kubik. Terdapat sebuah pulau ditengah Danau Toba yaitu Pulau Samosir.

Saat ini Danau Toba merupakan 1 (satu) dari 5 (lima) Destinasi Pariwisata Super Prioritas (DPSP) yang disiapkan oleh Pemerintah Indonesia. Penetapan kawasan Danau Toba sebagai salah satu destinasi pariwisata super prioritas adalah hal yang wajar mengingat keindahan alam Danau Toba yang terbentang di 7 (tujuh) Kabupaten yaitu Simalungun, Toba Samosir, Tapanuli Utara, Humbang Hasundutan, Dairi, Karo, dan Samosir. Bahkan Danau Toba sudah ditetapkan oleh Organisasi Pendidikan, Keilmuan dan Kebudayaan Perserikatan Bangsa-bangsa (UNESCO) sebagai UNESCO Global Geopark (UGG) ke-209 pada (2/7/2020) di Perancis.

Selain sebagai destinasi pariwisata super prioritas Danau Toba juga berfungsi utama Danau Toba saat ini adalah membangkitkan tenaga listrik lebih dari 1000 MW. Pembangkitan ini diantaranya menggunakan PLTA Sigura-gura dan PLTA Tangga dengan total kapasitas terpasang 604 MW (PLTA Asahan II, PLTA Asahan I (2 X 90 MW) dan PLTA Asahan di Simorea dan PLTA Asahan di Traktak yang mampu membangkitkan total daya listrik hingga 400 MW (Hotland Sihotang, dkk, 2012). 
Danau Toba memiliki potensi bencana gempa. Pada Selasa (11/5/2021) Badan Meteorologi, Klimatologi, dan Geofisika mencatat 10 (sepuluh) kali gempa beruntun mengguncang Kawasan Toba-Samosir. Kekuatan gempa bumi berkisar Magnitudo 1,5 - 3,1. Ahli Geologi menyatakan bahwa peningkatan intensitas gempa di Samosir dipicu oleh patahan Lau Renun. Patahan Lau Renun merupakan salah satu dari empat patahan yang terbentang di Pulau Sumatera. Tiga di antaranya melintas Sumut yakni patahan Lau Renun, patahan Angkola, dan patahan Barumun.

Danau Toba adalah perairan daratan yang memiliki peran multi -sektoral, baik kepentingan masyarakat lokal maupun kepentingan yang bersifat nasional, bahkan internasional (Lukman, 2013). Melihat kondisi bahwa Danau Toba merupakan wilayah perairan yang besar, memiliki beberapa potensi positif namun juga memiliki potensi bencana maka perlu adanya sistem yang mampu memberikan informasi pengendalian perairan di Danau Toba. Pada penelitian ini akan dibuat sebuah rancang bangun sistem untuk mengukur tinggi muka air di Wilayah Danau Toba.

\section{Tujuan dan Manfaat}

Rancang Bangun Sistem untuk mengukur tinggi muka air di Wilayah Danau Toba ini merupakan salah satu bentuk mitigasi yaitu upaya mengurangi resiko bencana dalam hal ini adalah peningkatan kemampuan dalam menghadapi ancaman bencana. Manfaat dari Rancang Bangun Sistem ini diharapkan dapat mendeteksi adanya bahaya atau ancaman melalui informasi perubahan tinggi muka air yang signifikan di Wilayah Danau Toba yang disebabkan oleh faktor cuaca maupun aktivitas tektonik maupun vulkanik di perairan wilayah Danau Toba sehingga dapat dilakukan antisipasi untuk mengurangi resiko bencana bagi masyarakat di Wilayah Danau Toba.

\section{METODE PENELITIAN}

\section{Pengamatan Tinggi Muka Air Danau}

Penyelenggaraan meteorologi, klimatologi, dan geofisika dalam UU 31 tahun 2009 tentang Meteorologi, Klimatologi dan Geofisika adalah untuk menghasilkan data dan informasi meteorologi, klimatologi dan geofisika yang memiliki peran strategis agar dapat dimanfaatkan di berbagai sektor terkait. Dalam Peraturan Pemerintah Nomor 46 Tahun 2012 tentang Penyelenggaraan Pengamatan dan Pengelolaan Data Meteorologi, Klimatologi, dan Geofisika. Penyelenggaraan pengamatan meteorologi dilakukan untuk memperoleh Data atau nilai gejala alam yang berkaitan dengan cuaca. Di mana salah satu unsur pengamatan meteorologi yang dimaksud adalah pasang surut air.

Pasang surut air identik dengan ruang lingkup lautan. Seluruh laut di seluruh dunia saling terhubung. Air bisa bergerak dan mengalir dengan bebas antar lautan. Air dapat mengalir dari laut yang mengalami surut ke laut yang mengalami pasang. Berbeda dengan lautan, perairan danau saling terisolasi. Danau-danau di seluruh dunia tidak saling terhubung. Akibatnya pasang yang besarnya signifikan tak mungkin terjadi pada danau.

Saat laut mengalami pasang naik, volume air bertambah, dan volume air ini dikirim dari lokasi lain yang mengalami surut. Air laut mengalir dari lokasi yang surut menuju lokasi yang pasang. Pada danau tidak terjadi mekanisme ini. Tidak ada tambahan volume air yang dapat diterima. Oleh karena itu pasang yang terjadi tidak signifikan. Perlu kajian mendalam untuk mendapatakan data secara akurat dinamika pasang-surut yang terjadi di danau. (Kjerfve B. 1994).

\section{Skema Perancangan sistem}

Rancang Bangun Sistem Monitoring Tinggi Muka Air di Danau Toba menggunakan beberapa komponen seperti Data Logger Campbell Scientific tipe CR6 dan Sensor Water Level Merk Campbell Scientific tipe SR-50AL.

Rancang Bangun Sistem Monitoring Tinggi Muka Air di Danau Toba ini juga dilengkapi dengan Sensor Hujan RM. Young 52203-20 dan Sensor Angin RM.Young 05103. Peralatan pendukung yang digunakan adalah solar panel, dan baterai sebagai catu daya. Rangkaian catu daya berfungsi untuk menyediakan arus dan tegangan tertentu sesuai dengan kebutuhan beban dari sumber daya listrik yang ada. Peralatan pendukung lainnya adalah modem GSM untuk pengiriman data. Blok diagram dapat dilihat pada Gambar 1. di bawah ini:

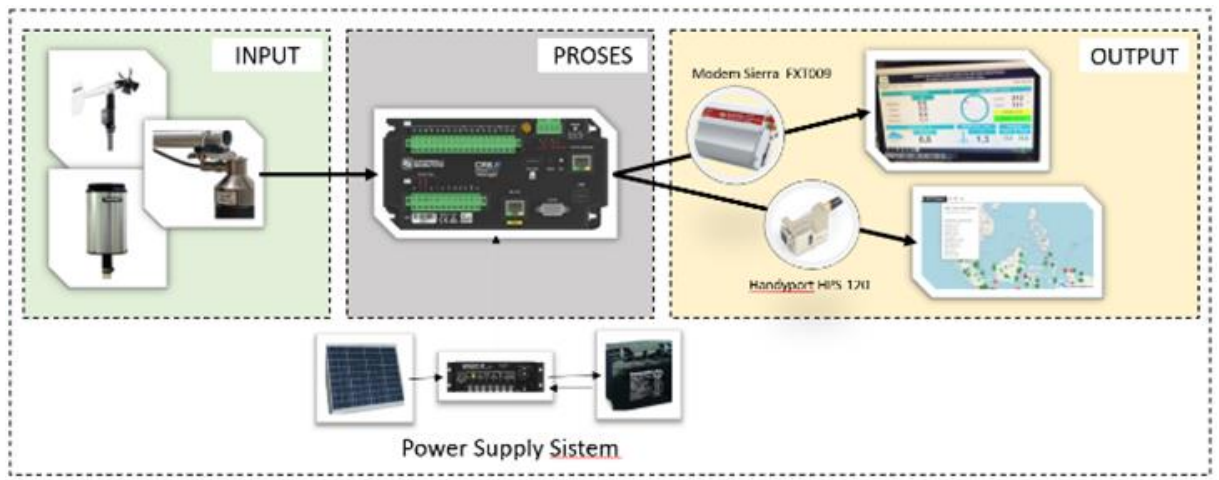

Gambar 1. Blok Diagram Rancang Bangun Sistem Monitoring Tinggi Muka Air Danau Toba 
Data logger merupakan sebuah perangkat elektronik yang berfungsi mengukur besaran listrik dari sensor baik analog maupun digital, kemudian melakukan perhitungan, dan memproses data menjadi nilai statistik. Data logger umumnya terdiri dari RTC, memori, port catu daya, port komunikasi, Analog To Digital Converter (ADC), port input serta output. Data logger yang digunakan dalam rancang bangun ini adalah Data Logger Merk Campbell Scientific Tipe CR6. Data logger CR6 merupakan data logger yang mudah diimplementasikan untuk penelitian lapang (Singh, A., \& Perry, M. 2016)

Sensor Water Level adalah sensor yang mengukur perubahan jarak tinggi muka air terhadap sensor. Sensor yang digunakan dalam rancang bangun ini adalah sensor water level merk Campbell Scientific tipe SR50A-L. Prinsip kerja sensor ini didasari oleh pantulan gelombang ultrasonik, selang waktu yang dibutuhkan antara pancaran gelombang ultrasonik dan target (permukaan) dikonversi menjadi jarak antara sensor.

Sensor Water Level mendeteksi perubahan tinggi muka air dan mengirimkan informasi tersebut ke Data Logger. Koneksi antara sensor Water Level SR-50AL. dengan data logger CR6 menggunakan antarmuka port SDI-12 yakni protokol komunikasi serial asinkronus yang biasa digunakan pada sensor untuk memantau parameter lingkungan.

Informasi dari sensor yang diterima oleh Data Logger diolah dan hasil pengolahan berupa data tinggi muka air dan keterangan waktu ditampilkan secara real time pada display pelabuhan menggunakan media komunikasi berupa Handyport-120 dan dikirim ke server dalam bentuk paket string yang dilengkapi dengan identitas lokasi untuk ditampilkan di website yang dirancang menggunakan bahasa pemrograman PHP, Javascript, HTML dan CSS3. Sistem pemantauan data berbasis website untuk memudahkan user untuk mengetahui data water level secara real time maupun kumulatif berdasarkan rentang waktu yang diinginkan oleh user agar dapat diproses sesuai kebutuhan user.

Sistem Monitoring Tinggi Muka Air di Danau Toba dibangun di 6 (enam) lokasi yaitu Pelabuhan Ajibata, Pelabuhan Ambarita, Pelabuhan Simanindo, Pelabuhan Muara, Pelabuhan Sippingan, Pelabuhan Balige.

\section{Metode Pengukuran}

Pengukuran tinggi muka air dilakukan dengan melakukan pengukuran antara titik 0 palem dengan permukaan air lalu dengan menghitung selisih pengukuran tinggi muka air yang terbaca oleh sensor dengan ketinggian muka air yang terbaca oleh palem. Tujuan pengukuran tinggi muka air dilakukan untuk memperoleh nilai Y (sesuai gambar 4.). Nilai $\mathrm{Z}$ adalah jarak dari dasar titik pengukuran ke sensor. Nilai $\mathrm{Z}$ ini dipastikan dengan adanya pemasangan tide staff. Nilai $\mathrm{X}$ adalah jarak sensor ke permukaan air. Sehingga diperoleh nilai $\mathrm{Y}$, yaitu tinggi muka air yang merupakan selisih dari tinggi dasar ke sensor dikurangi jarak sensor ke permukaan air.

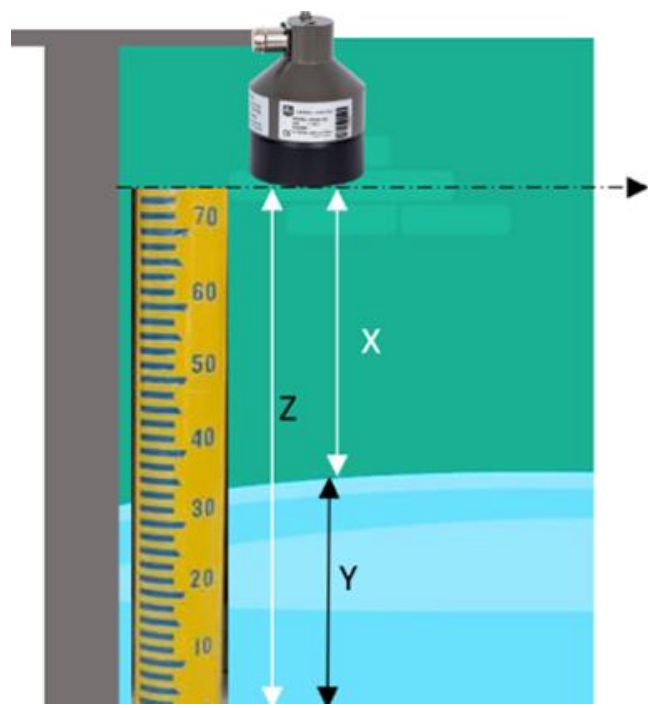

Gambar 2. Ilustrasi Pengukuran Tinggi Muka Air Danau Toba

\section{HASIL DAN PEMBAHASAN}

Hasil pengukuran yang diperoleh dari sensor ditampilkan pada display cuaca pelabuhan dan dikirim ke server. Data yang ditampilkan merupakan data pengukuran tinggi muka air, yang merupakan selisih dari tinggi dasar ke sensor dikurangi jarak sensor ke permukaan air. 

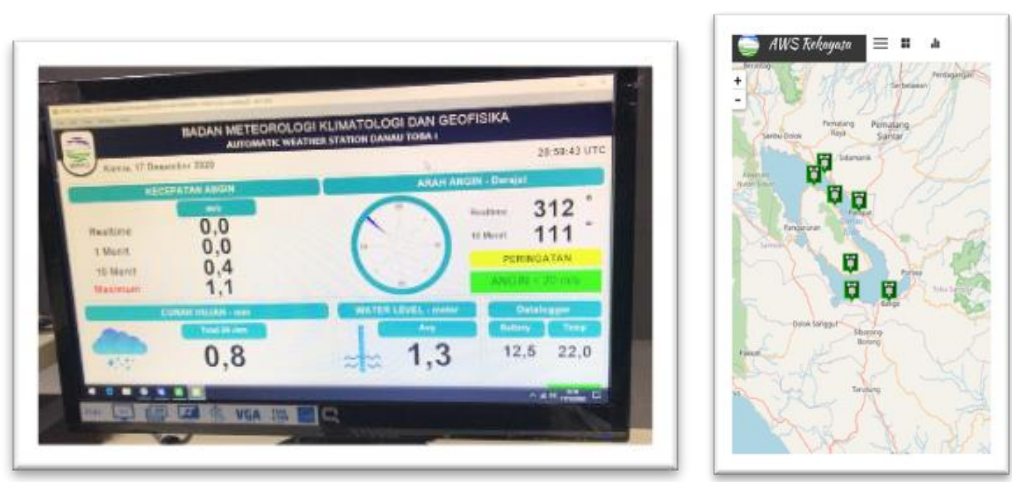

Gambar 3.Display cuaca pelabuhan dan tampilan website

Berikut data per satu menit tinggi muka air Danau Toba yang dihasilkan oleh AWL yang sudah terpasang pada tanggal 01 - 07 Mei 2021 yang diperoleh dari enam lokasi AWL Danau Toba.
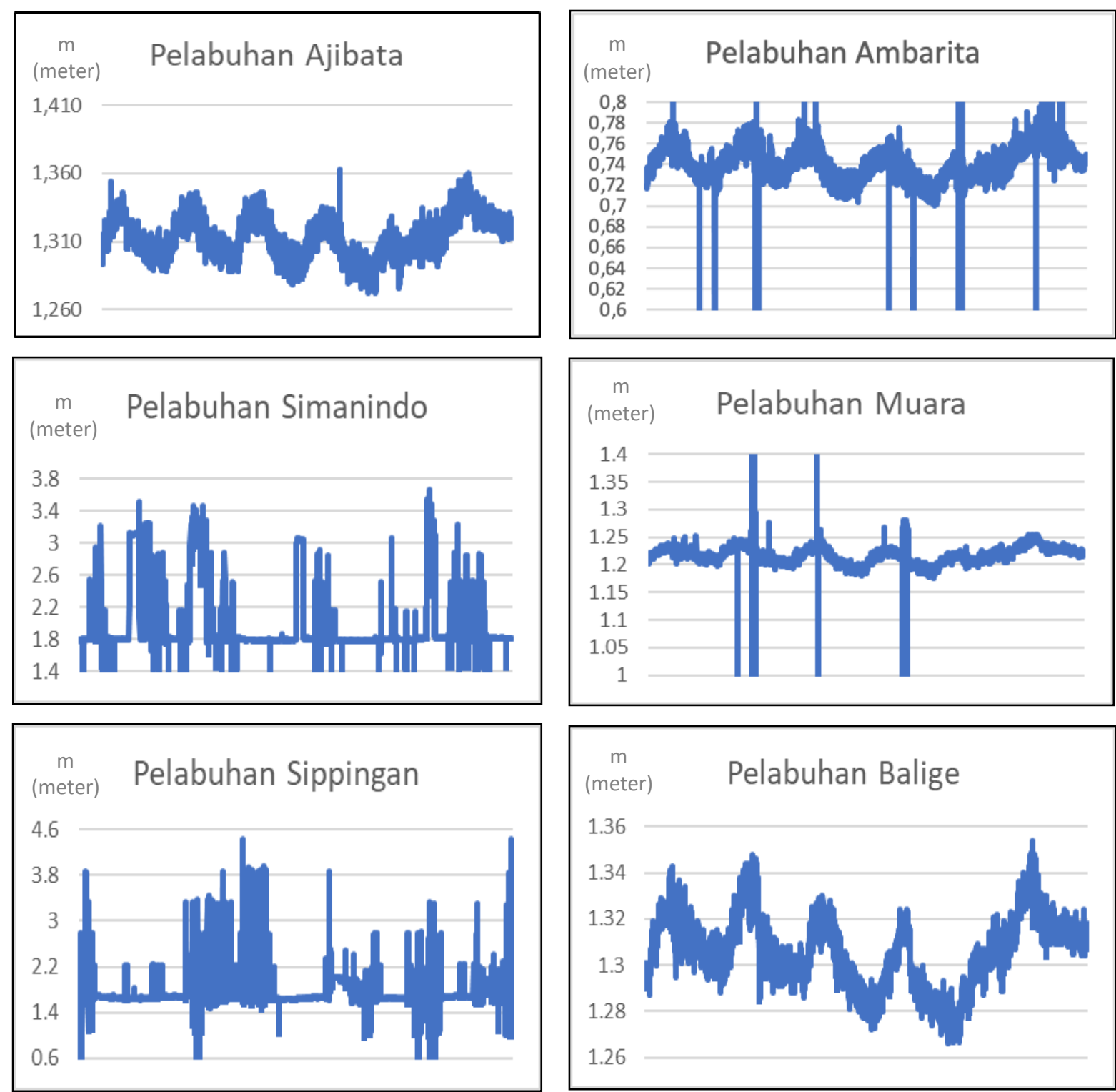

Gambar 4. Data Tinggi Muka Air Pelabuhan Ajibata, Ambarita, Simanindo, Muara, Sippingan, dan Balige 
Sistem Monitoring Tinggi Muka Air yang dipasang di Pelabuhan Ajibata mampu menghasilkan data yang baik dan kontinyu. Data menunjukkan adanya perubahan nilai terukur yaitu sensor ke permukaan air yang tidak signifikan pada kisaran 1,270 hingga 1,360 meter. Data terukur maksimal 1,363 meter dan data minimal terukur 1,272 meter. Tidak terdapat loss data selama pengukuran. Terdapat spikes namun hanya muncul di beberapa waktu.

Pada grafik data Pelabuhan Ambarita, Simanindo, Muara, dan Sippingan dapat diamati beberapa data mengalami penyimpangan.. Hal ini bisa disebabkan beberapa faktor salah satunya adanya noise yang terukur berupa objek lain yang mengganggu pengukuran sensor ultrasonik.. Grafik tinggi muka air pada Pelabuhan Balige menunjukan hasil yang cukup baik dan kontinyu, walaupun terdapat beberapa data yang menyimpang dari grafik diatas, namun tidak terlalu banyak. Perubahan secara jauh ini bisa disebabkan beberapa faktor salah satunya adalah Kapal yang bersandar ataupun pergi dari pelabuhan yang menyebabkan adanya perubahan tinggi muka air pada sekitar pelabuhan Balige. Grafik di pelabuhan Balige menunjukan nilai pada kisaran 1,26 meter hinggal 1,35 meter, dengan data terukura maksimal sebesar 1,354 meter den terendah 1, 266 meter.

\section{KESIMPULAN}

Secara keseluruhan sensor water level yang dipasang pada keenam lokasi Danau Toba berhasil dirancang dan menghasilkan data yang cukup baik. Sensor mampu mengidentifikasi perubahan tinggi muka air dengan amplitudo kecil yaitu 10 - 15 centimeter. Pada penelitian berikutnya, sensor water level perlu dilengkapi beberapa kelengkapan seperti rambu pasang surut atau palem yang dilevelling dan diikatkan dengan titik tetap di daratan yaitu Titik Acuan Palem (TAP) serta BM (Bench Marking). Proses kalibrasi juga diperlukan untuk mengetahui nilai koreksi dan ketidakpastian dari sensor.

\section{DAFTAR PUSTAKA}

Hotland Sihotang, dkk (2012) Model Konservasi Sumberdaya Air Danau Toba. Jurnal Pengelolaan Sumber Daya Alam dan Lingkungan Vol. 2 No. 2 (Desember 2012): 65-72

http://disbudpar.sumutprov.go.id/objek_wisata/danau-toba

Kjerfve B. 1994. Coastal lagoons. In Kjerfve, B. (ed.), Coastal Lagoon Processes. Elsevier Oceanography Series, 60 : $1-8$

Lukman (2013). Danau Toba: Karakteristik Limnologis dan Mitigasi Ancaman Lingkungan dari Pengembangan Jaring Apung. LIPI Press

Singh, A., \& Perry, M. (2016, June). Development of a new controller for absolute cavity radiometer for cavity calibration and solar irradiance measurement. In 2016 IEEE 43rd Photovoltaic Specialists Conference (PVSC) (pp. 1013-1015). IEEE.

Zuli Istataqomawan, dkk. Catu Daya Tegangan DC Variabel dengan Dua Tahap Regulasi (Switching dan Linier). Teknik Elektro Universitas Diponegoro 